\title{
Desain Konsep Solar Energy Assisted Water Bus sebagai Sarana Transportasi Rute Marunda-Muara Baru, Jakarta
}

\author{
I Wayan Suputra, Ahmad Nasirudin, dan Gita Marina \\ Departemen Teknik Perkapalan, Fakultas Teknologi Kelautan, Institut Teknologi Sepuluh Nopember (ITS) \\ e-mail: anasirudin@na.its.ac.id
}

\begin{abstract}
Abstrak-Kapal penumpang sebagai sarana antar jemput terjadwal bagi warga Marunda untuk menghindari kepadatan lalu lintas darat menuju Muara Baru Jakarta, menempuh jarak 10.26 mil dengan mengangkut rata-rata 20 penumpang per hari. Namun dengan penggerak kapal yang masih menggunakan BBM, pengoperasian kapal hingga akhir 2016 sempat mengalami kendala, karena telatnya pasokan BBM menyebabkan kapal penumpang berhenti beroperasi. Tugas Akhir ini bertujuan mendesain water bus sebagai kapal penumpang dengan pelayanan terjadwal, yang memanfaatkan energi matahari sebagai sumber energi untuk penggerak kapal agar mengurangi penggunaan kendaraan bermotor dan penggunaan BBM. Metode yang di gunakan dalam mendesain kapal ini yaitu metode trend curve approach. Ukuran utama kapal yang didapat adalah $\mathrm{LOA}=9.71 \mathrm{~m}, \mathrm{~B}=3.15 \mathrm{~m}, \mathrm{~T}=0.56$ $\mathrm{m}, \mathrm{H}=1.17 \mathrm{~m}, \mathrm{~B} 1=1.06 \mathrm{~m}, \mathrm{Cb}=0.409$, dan $\mathrm{Vs}=11$ knots dengan kapasitas jumlah penumpang 20 orang. Daya baterai sebesar $60 \mathrm{Kwh}$ dan daya panel surya yang terpasang sebesar 3000 Wp.
\end{abstract}

Kata Kunci-Marunda, Solar energy, Trend curve approach, Water Bus.

\section{PENDAHULUAN}

K ONSUMSI energi sektor transportasi di Indonesia pada tahun 2010 hingga 2015 masih didominasi oleh Bahan Bakar Minyak (BBM) dengan konsumsi final sebesar 178 juta Barrel Oil Equivalent [1]. Ketergantungan pada konsumsi BBM dapat membawa dampak negatif, seperti pada kasus kapal penumpang yang menghubungkan rute dermaga ujung Banjir Kanal Timur (BKT Marunda) dengan dermaga Muara Baru yang pernah tidak beroperasi karena telatnya pasokan BBM [2].

Motor elektrik dapat digunakan sebagai solusi untuk menggantikan penggunaan mesin konvensional dalam mengurangi permasalah yang disebutkan di atas. Kebutuhan akan BBM diganti dengan baterai yang dapat diisi dengan menghubungkan langsung ke jaringan pengisian (grid). Pemasangan sumber energi terbarukan perlu dilakukan untuk mengontrol ketergantungan penggunaan grid [3], seperti pada saat mati listrik atau saat terjadi bencana yang menyebabkan jaringan pengisian listrik terganggu.

Jakarta merupakan kota dengan tingkat kemacetan tertinggi ke-12 di dunia dengan rata-rata lama waktu kemacetan mencapai 63 jam dalam setahun [4]. Sebagai solusi maka perlu dikembangkan desain sarana transportasi air berupa kapal penumpang dengan menggunakan sumber energi non-BBM dengan bantuan panel surya sebagai energi terbarukan. Tujuanya untuk mengatasi ketergantungan akan penggunaan penggunaan BBM berlebih sekaligus sebagai sarana agar terhindar dari kemacetan.

\section{TINJAUAN PUSTAKA}

\section{A. Teori Desain Kapal}

Proses mendesain kapal adalah proses berulang, yaitu seluruh perencanaan dan analisis yang dilakukan secara berulang demi mencapai hasil yang maksimal ketika desain tersebut dikembangkan. Desain ini digambarkan pada desain spiral (the spiral design). Desain spiral membagi seluruh proses menjadi 4 tahapan yaitu: (a.) Concept Design, dimana desainer menggunakan rumus pendekatan, kurva ataupun pengalaman untuk membuat perkiraan-perkiraan awal. (b.) Preliminary Design merupakan usaha teknis lebih lanjut yang akan memberikan lebih banyak detail pada concept design. (c.) Contract Design yakni tahap pengembangan pendesainan kapal dalam bentuk yang lebih mendetail agar pembangun kapal memahami kapal yang akan dibuat dan mengestimasi secara akurat seluruh biaya pembuatan kapal untuk membuat dokumen kontrak. (d.) Detail Design tahap terakhir dari proses mendesain kapal. Pada tahap ini hasil dari tahapan sebelumnya dikembangkan menjadi gambar kerja yang lebih detail secara menyeluruh untuk kepentingan produksi kapal [5].

\section{B. Metode Desain Kapal}

Metode-metode dalam pendesainan kapal dapat dijabarkan antara lain:, (a.) Parent Design Approach, dimana mendesain kapal dengan cara mengambil sebuah kapal yang dijadikan sebagai acuan kapal pembanding yang memiliki karakteristik yang sama dengan kapal yang akan dirancang. (b.) Trend Curve Approach, dengan metode statistik memakai sistem regresi dari beberapa kapal pembanding untuk menentukan ukuran utama kapal. (c.) Iterative Design Approach, metode mendesain kapal yang berdasarkan pada proses siklus dari prototyping, testing, dan analyzing. (d.) Optimization Design Approach, desain yang optimum dicari dengan menemukan desain yang akan meminimalkan economic cost (biaya ekonomi agar seminimal mungkin).

\section{Katamaran}

Katamaran adalah kapal yang memiliki dua lambung atau badan yang dihubungkan oleh geladak ditengahnya. Katamaran cenderung untuk menghasilkan hambatan lebih kecil pada kecepatan yang sama dengan monohull. Semakin lebar jarak pisah antar lambung, maka semakin rendah hambatan katamaran [6].

Karamaran memiliki beberapa kelebihan jika dibandingkan dengan kapal monohull meliputi tahanan gesek yang lebih kecil; luas geladak yang lebih luas; stabilitas kapal yang lebih tinggi; sudut oleng yang relatif rendah. Namun katamaran juga memiliki kekurangan seperti: masih tergolong teknologi yang baru;teknik 
pembuatan yang lebih rumit; kemampuan manuver yang kurang baik jika dibandingkan dengan kapal monohull.

\section{Sistem Panel Surya}

Sistem panel surya pada desain ini berupa panel surya, baterai dan charge controller. Panel surya merupakan rangkaian dari sel surya photovoltaic (PV) yang saling berhubungan dan dikemas di antara dua lapis bahan transparan [7]. Sel surya menghasilkan daya listrik dengan mengubah radiasi matahari menjadi arus listrik searah (DC) dengan menggunakan semikonduktor melalui efek fotovoltaik. Daya keluaran pada tiap panel $\left(\mathrm{E}_{\mathrm{P}}\right)$ bergantung pada faktor-faktor seperti waktu rata-rata penyinaran matahari perhari dalam jam $\left(\mathrm{T}_{\mathrm{ss}}\right)$, daya yang didesain untuk tiap panel dalam watt hour $\left(\mathrm{W}_{\mathrm{P}}\right)$, serta faktor koreksi suhu $\left(\mathrm{T}_{\mathrm{CF}}\right)$, yang dirumuskan sebagai;

$$
\mathrm{E}_{\mathrm{P}}=\mathrm{W}_{\mathrm{P}} * \mathrm{~T}_{\mathrm{SS}} * \mathrm{~T}_{\mathrm{CF}}
$$

Baterai berfungsi sebagai tempat penyimpanan energi listrik. Kapasitas baterai dinyatakan dalam ampere jam (Ah = kuat arus/Ampere $\mathrm{x}$ waktu/hour), artinya baterai dapat memberikan/menyuplai sejumlah isinya secara rata-rata sebelum tiap selnya menyentuh tegangan/voltase turun (drop voltage). Energi yang ditampung dalam baterai besarnya dipengaruhi oleh tegangan nominal baterai dalam volt $\left(\mathrm{V}_{\text {batt }}\right)$, kapasitas baterai dalam Ampere-jam ( $\left.\mathrm{C}_{\text {batt }}\right)$, efisiensi pemakaian baterai ( $\eta \mathrm{d})$ dan jumlah baterai yang akan digunakan $\left(\mathrm{x}_{2}\right)$. Faktor-faktor tersebut dirumuskan sebagai Battery Energy [8].

$E_{\text {batt }}=\frac{V_{\text {batt }} \cdot C_{\text {batt }} \cdot x_{2}}{1000 \cdot \eta_{d}}$

Fungsi dari charge controller adalah mengatur arus dari panel surya untuk mencegah baterai dari pengisian yang berlebihan. Charge controller mendeteksi ketika baterai terisi penuh kemudian menghentikan arus yang mengalir ke baterai dan juga mencegah baterai mengalirkan arus kembali ke panel surya di malam hari ketika gelap.

\section{E. Tinjauan Lokasi}

Menurut penelusuran melalui peta di internet, wilayah Marunda terletak pada 6"07' LS (Lintang Selatan) dan 106"57' BT (Bujur Timur) dengan update terakhir tahun 2017. Secara administratif Marunda merupakan salah satu kelurahan yang menjadi bagian dari Kotamadya Jakarta Utara. Sebelah timur wilayah Marunda terdapat sungai Kanal Banjir Timur (KBT). Sungai KBT sebagai saluran air yang melintasi 13 kelurahan di Jakarta Utara dengan panjang saluran $\pm 23,5 \mathrm{~km}$ serta kedalaman $7 \mathrm{~m}$ pada hilirnya [9] .

Pada tahun 2013 tidak kurang dari 1800 warga Muara Baru, Penjaringan direlokasi ke wilayah Marunda karena diadakan normalisasi Waduk Pluit. Mereka mendapatkan fasilitas berupa dermaga dan kapal penumpang yang lokasinya dijelaskan pada Gambar 1.

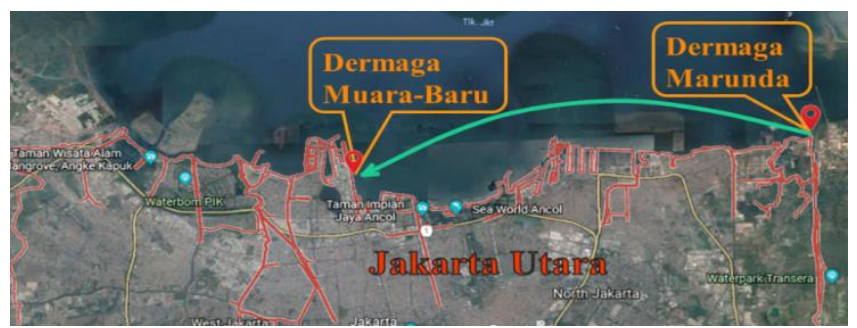

Gambar 1. Lokasi dermaga apung Marunda (keberangkatan) dan dermaga apung Muara Baru (Kedatangan).
Dermaga, kapal penumpang, beserta perangkatnya dikelola oleh Unit Pengelola Angkutan Perairan dan Kepelabuhan (UP-APK) dibawah Pemerintah Provinsi DKI Jakarta. Dermaga dan kapal penumpang yang posisinya berada di hilir sungai KBT, berfungsi sebagai sarana antar jemput bagi warga relokasi ke tempat kerjanya di Muara Baru.

\section{METODOLOGI PENELITIAN}

\section{A. Pengumpulan Data}

Pengumpulan data dilakukan secara tidak langsung (data sekunder). Data-data ini yang nantinya akan menjadi parameter dan referensi dalam proses desain kapal. Data yang dibutuhkan antara lain:

a. Data jumlah penumpang yang menyeberang

b. Jarak pelayaran

c. Data kapal penumpang katamaran yang menggunakan sel surya.

\section{B. Analisis Data}

Tujuan dari analisis data ini adalah untuk memperoleh nilai payload kapal berupa jumlah penumpang yang akan diangkut oleh kapal yang didesain.

\section{Ukuran Utama Kapal}

Penentuan ukuran utama pada proses mendesain kapal ini menggunakan metode Trend Curve Approach atau regresi linier dengan cara menarik rumusan dari kumpulan data kapal pembanding yang karakteristiknya sama.

\section{Analisis Teknis}

Perhitungan teknis yang dilakukan meliputi perhitungan rasio ukuran utama, perhitungan nilai hambatan, perhitungan kebutuhan daya kapal, pemilihan motor penggerak, perhitungan daya oleh panel surya, perhitungan berat, koreksi displacement, koreksi freeboard, trim, dan stabilitas kapal.

\section{E. Desain Model}

Pada tahap ini dilakukan perencanaan terhadap kapal yang didesain dengan memperhatikan beberapa pertimbangan seperti kenyamanan penumpang, penyediaan akses yang cukup dan stabilitas. Sehingga didapatkan desain yang sesuai dengan payload dan jalur pelayaran. Perencanaan yang dilakukan adalah sebagai berikut:

a. Desain Rencana Garis

b. Desain Rencana Umum dan Safety plan

c. Desain 3 Dimensi

\section{F. Hasil Penelitian}

Setelah dilakukan analisis dan desain model yang sudah sesuai dapat diperoleh hasil penelitian. Hasil penelitian ini yang dapat dijadikan referensi untuk penelitian selanjutnya.

\section{ANALISIS TEKNIS}

\section{A. Penentuan Payload}

Penentuan payload pada desain ini mengacu pada data hasil survey berupa daftar manifes penumpang pada kapal penyeberangan yang sudah ada namun sedang tidak beroperasi saat survey penulis. Dari daftar manifes perhari dilakukan rekapitulasi sehingga didapat total penumpang dan jumlah keberangkatan dalam tiap tahun selama 2015 sampai dengan 2016 dimana kapal masih beroperasi. Jumlah 
keberangkatan selama tahun 2015 sebanyak 287 kali dengan mengangkut 5771 penumpang, maka jumlah rata-rata penumpang yang diangkut tiap keberangkatan selama tahun 2015 sebanyak 21 penumpang. Untuk jumlah rata-rata penumpang yang diangkut tiap keberangkatan selama tahun 2016 sebanyak 19 orang. Payload diambil dari jumlah ratarata penumpang yang diangkut tiap keberangkatan selama tahun 2015 dan 2016 sebanyak 20 orang.

\section{B. Penentuan Ukuran Utama Kapal}

Nilai ukuran utama ditentukan menggunakan metode Trend Curve Approach atau regresi linier, dengan cara menarik persamaan dari kumpulan data kapal pembanding yang karakteristiknya sama dan sudah pernah dibangun. Data kapal pembanding dapat dilihat pada Tabel 1.

Tabel 1.

Data ukuran kapal pembanding

\begin{tabular}{|c|c|c|c|c|c|c|}
\hline \multirow[b]{2}{*}{ No } & \multirow[b]{2}{*}{ Nama Kapal } & \multicolumn{4}{|l|}{ Ukuran } & \multirow{2}{*}{$\begin{array}{c}\text { Passenger } \\
\text { (Person) }\end{array}$} \\
\hline & & $\mathrm{L}(\mathrm{m})$ & $\begin{array}{c}\mathrm{B} \\
(\mathrm{m})\end{array}$ & $\begin{array}{c}\mathrm{T} \\
(\mathrm{m})\end{array}$ & $\begin{array}{c}\mathrm{D} \\
(\mathrm{m})\end{array}$ & \\
\hline 1 & Sun Cr Z9 & 3.30 & 1.65 & 0.3 & 0.64 & 4 \\
\hline 2 & E-Maran 8 & 6.50 & 2.3 & 0.28 & 1.04 & 8 \\
\hline 3 & $\begin{array}{l}\text { SunRider (12 } \\
\text { Pass) }\end{array}$ & 6.50 & 2.5 & 0.5 & 1.1 & 12 \\
\hline 4 & E-Maran 16 & 8.80 & 2.3 & 0.32 & 1.04 & 16 \\
\hline 5 & $\begin{array}{l}\text { SunRIder (20 } \\
\text { Pass) }\end{array}$ & 9.00 & 3 & 0.6 & 1.1 & 20 \\
\hline 6 & Sun Cr Z30 & 9.20 & 3 & 0.6 & 1.1 & 20 \\
\hline 7 & FBI 1032 KA & 10.30 & 3.2 & 0.55 & 1.2 & 20 \\
\hline 8 & JC-1032 & 10.50 & 3.4 & 0.6 & 1.2 & 20 \\
\hline 9 & $\begin{array}{l}\text { FRP Catamaran } \\
\text { China }\end{array}$ & 10.80 & 3.8 & 0.67 & 1.3 & 25 \\
\hline
\end{tabular}

Data ukuran kapal pada Tabel 1 diplot kedalam grafik pada Gambar 2. Penarikan persamaan linear pada grafik dalam proses regresi menggunakan software pengolah data.

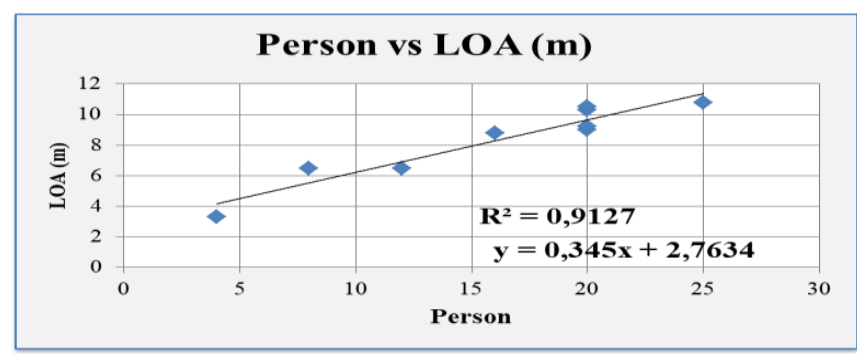

Gambar 2. Grafik hubungan LOA (panjang keseluruhan kapal dalam meter) dengan Person (jumlah penumpang).

Persamaan linear sebagai hasil regresi dari setiap ukuran utama dihitung lalu direkap pada Tabel 2.

Tabel 2.

Ukuran utama kapal penumpang (waterbus) katamaran

\begin{tabular}{llccc}
\hline \hline Ukuran & Rumus & R2 & Nilai & Satuan \\
\hline LoA & $0.345 * \mathrm{P}+2.7634$ & 0.9127 & 9.71 & $\mathrm{~m}$ \\
$\mathrm{~B}$ & $0.0911 * \mathrm{P}+1.3267$ & 0.8717 & 3.15 & $\mathrm{~m}$ \\
$\mathrm{H}$ & $0.0234 * \mathrm{P}+0.0735$ & 0.7319 & 1.17 & $\mathrm{~m}$ \\
$\mathrm{~T}$ & $0.019 * \mathrm{P}+0.1857$ & 0.7527 & 0.56 & $\mathrm{~m}$ \\
\hline \hline
\end{tabular}

Penentuan ukuran lambung katamaran menggunakan referensi perbandingan ukuran dari salah satu model lambung pada pengujian komponen hambatan kapal katamaran oleh Insell dan Molland [10]. Sehingga didapatkan nilai lebar demihull $\left(\mathrm{B}_{1}\right)=1.06 \mathrm{~m}$ dan jarak pisah lambung $(\mathrm{S})=2.09 \mathrm{~m}$.

\section{Pembuatan Model Lambung}

Pembuatan model lambung menggunakan referensi dari linesplan model pada percobaan Insell dan Molland. Dari referensi linesplan kemudian dilakukan penggambaran ulang dengan bantuan software $3 D$ Modelling sampai karakteristik lambung yang didesain mendekati nilai koefisien pada referensi linesplan. Hasil desain 3D model lambung dapat dilihat pada Gambar 3.

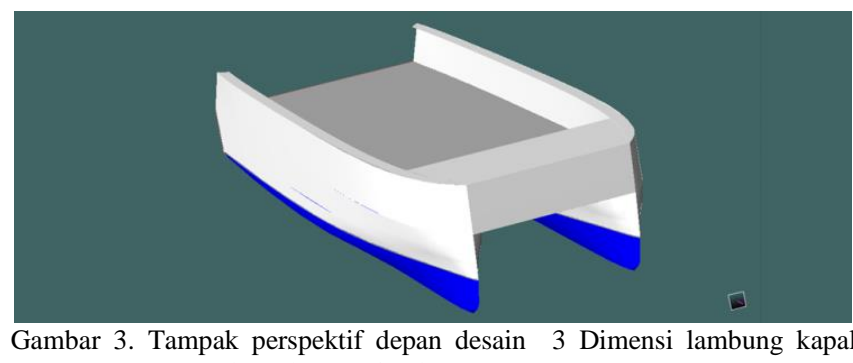
penumpang (water bus) dengan tipe katamaran.

\section{Perhitungan Awal}

Perhitungan awal yang dilakukan adalah perhitungan Froude Number serta perhitungan koefisien ( $\mathrm{Cm}$ dan Cwp) [11]. Nilai koefisien lain seperti $C_{B}$ dan $C_{P}$ diperoleh melalui hasil perhitungan oleh software $3 D$ Modelling.

\section{E. Perhitungan Hambatan dan Propulsi}

Perhitungan hambatan total $\left(\mathrm{R}_{\mathrm{T}}\right)$ dilakukan dengan menggunakan bantuan software. Metode yang digunakan yaitu Analytical Slender Body. Nilai hambatan total yang didapat dari perhitungan sebesar $2.637 \mathrm{kN}$.

Nilai thrust power yang dibutuhkan untuk menggerakkan kapal dihitung menggunakan rumus propulsi [12], sehigga didapatkan kebutuhan daya sebesar $14.957 \mathrm{~kW}$. Motor penggerak yang dipilih yaitu motor tempel berjumlah 2 buah dengan thrust power untuk 1 mesin sebesar $7.965 \mathrm{~kW}$ dan brake power sebesar $15,5 \mathrm{~kW}$.

\section{F. Penentuan Kebutuhan Daya Listrik dan Kapasitas Baterai}

Kebutuhan daya 1 trip merupakan total daya yang dibutuhkan untuk propulsi dan peralatan navigasi komunikasi. Untuk daya dua buah motor (brake power) pada kecepatan dinas, dibutukan sebesar $31 \mathrm{~kW}$. Sedangkan untuk peralatan navigasi dan komunikasi sebesar $0.139 \mathrm{~kW}$. Kebutuhan daya 1 trip didapatkan sebesar $31.139 \mathrm{~kW}$. Dari 2 trip yang direncanakan dengan waktu tempuh pada kecepatan dinas adalah 2 jam dalam sehari beroperasi, maka energi yang terpakai sebesar $62.28 \mathrm{kWh}$ per-harinya. Untuk memenuhi kebutuhan daya (Ebatt) sebesar $62.28 \mathrm{kWh}$, jumlah baterai yang dipilih dapat dihitung dengan persamaan (2). Untuk mendapatkan nilai $\mathrm{x}_{2}$ maka persamaan (2) menjadi;

$$
x_{2}=\frac{E_{\text {batt }} \cdot 1000 \cdot \eta_{d}}{V_{\text {batt }} \cdot C_{\text {batt }}}
$$

Dengan mengambil nilai $\eta \mathrm{d}=85 \%$ dan Cbatt $=160 \mathrm{Ah}$, maka dari perhitungan didapatkan nilai $\mathrm{x}_{2}$ sebanyak 8 buah untuk dua mesin. Pada sistem penggerak twin screw direncanakan memiliki 4 buah baterai yang digunakan pada masing-masing mesin. Kapasitas energi yang mampu disimpan dalam baterai sebesar $75 \mathrm{kWh}$ jika dihitung dengan persamaan (2).

\section{G. Perencanaan Jumlah Panel Surya}

Panel surya direncanakan peletakanya di atap kapal, sehingga luas atap kapal yang digunakan menentukan jumlah panel surya. Luas atap yang direncanakan berasal dari sketsa pada layout awal. Luas geladak pada layout awal sebesar $21.364 \mathrm{~m}^{2}$, maka direncanakan luas atap sebesar 
$20.832 \mathrm{~m}^{2}$. Dimensi panel 1196 x 541 x 40 (dalam mm) sehingga dengan perencanaan panel surya yang dapat dipasang pada atap kapal sejumlah 30 buah. Maka daya yang dapat dihasilkan oleh kumpulan panel surya sebesar 3000 Wp untuk penyinaran matahari selama 4.97 jam [13], dimana energi yang dihasilkan oleh panel surya hanya dapat melingkupi sebesar $24 \%$ kebutuhan energi total.

\section{H. Perhitungan Tebal Lambung}

Untuk perhitungan tebal kulit menggunakan klasifikasi BKI (Biro Klasifikasi Indonesia) kapal khusus berukuran kecil dibawah 24 meter. Desain kapal ini direncanakan menggunakan bahan fiberglass. Penentuan tebal kulit berdasarkan nilai berat lapisan (Glass of weight) masingmasing bagian [14]. Hasil perhitungan tebal kulit dapat dilihat pada Tabel 3 dibawah.

Tabel 3.

Ketebalan lapisan kulit pada setiap bagian lambung kapa

\begin{tabular}{llrrl}
\hline \hline \multirow{2}{*}{ Tebal } & Shell Bottom & $4.72 \mathrm{~mm}$ & $\approx 5 \mathrm{~mm}$ \\
\cline { 2 - 4 } Kulit & Shell Side & $4.15 \mathrm{~mm}$ & $\approx 5 \mathrm{~mm}$ \\
\cline { 2 - 4 } & Deck house & $4 \mathrm{~mm}$ & $\approx 4 \mathrm{~mm}$ \\
\hline \hline
\end{tabular}

\section{Perhitungan Berat Kapal}

Perhitungan berat kapal terbagi dua yaitu DWT dan LWT. DWT adalah berat muatan kapal yaitu penumpang dan crew, sedangkan LWT adalah berat kapal kosong ditambah sistem propulsi dan equipment. Total berat LWT dan DWT seperti yang dijelaskan di Tabel 4 yaitu 4.928 ton.

Tabel 4.

Total berat DWT dengan LWT kapal penumpang

\begin{tabular}{clcc}
\hline \hline No & Komponen Berat Kapal & Value & Unit \\
\hline 1 & Berat Kapal Bagian DWT & 1,84 & ton \\
2 & Berat Kapal Bagian LWT & 2,81 & ton \\
Total & & 4,928 & ton \\
\hline \hline
\end{tabular}

Gaya angkat dari hasil pemodelan lambung sebesar 5.041 ton, sehingga selisih gaya angkat dengan LWT dan DWT sebesar 0.116 ton atau sebesar $2.2 \%$.

\section{J. Perhitungan Freeboard}

Freeboard atau lambung timbul merupakan selisih antara tinggi kapal dengan tinggi sarat air yang berfungsi sebagai daya apung cadangan. Perhitungan lambung timbul menggunakan ketentuan NCVS (Non-Convention Vessel Standard) Indonesian Flag Chapter VI [15]. Tinggi lambung timbul menurut NCVS Chapter VI Appendix 5 tidak boleh kurang dari $250 \mathrm{~mm}$ untuk kapal dengan panjang $\leq 15 \mathrm{~m}$ yang berlayar di laut terbatas. Dari hasil pengurangan tinggi geladak dengan tinggi sarat didapatkan nilai lambung timbul aktual sebesar 0,61 m sehingga masih memenuhi persyaratan.

\section{K. Analisis Stabilitas}

Analisis stabilitas bertujuan untuk mengetahui keseimbangan kapal secara melintang pada kondisi pemuatan tertentu. Analisis stabilitas pada desain kapal ini menggunakan bantuan software. Kriteria stabilitas yang digunakan sebagai batasan adalah kriteria stabilitas untuk kapal penumpang katamaran yang mengacu pada HSC Code 2000 Annex 7 [16].

Kondisi pemuatan untuk analisis stabilitas pada desain ini yaitu saat kapal membawa muatan penuh sebanyak 20 penumpang, setengah penumpang, penumpang kosong dan kondisi pemuatan penumpang yang menumpuk pada salah satu sisi kapal. Salah satu analisis stabilitas pada kondisi penumpang penuh disajikan pada Tabel 5.

Tabel 5.

Kriteria stabilitas melintang kapal untuk kondisi 20 penumpang

\begin{tabular}{lcccc}
\hline \hline Criteria & Syarat & Value & Satuan & Status \\
\hline $\begin{array}{l}\text { Area 0 to } 30 \\
\begin{array}{l}\text { Angle of } \\
\text { Maximum }\end{array}\end{array}$ & Value $\geq 4.727 \mathrm{~m} . \mathrm{deg}$ & 8.851 & $\mathrm{~m} . \mathrm{deg}$ & Pass \\
$\begin{array}{l}\text { GZ(intact) } \\
\begin{array}{l}\text { Area between GZ } \\
\text { and HTL }\end{array}\end{array}$ & Value $\geq 10$ & 20 & $\mathrm{deg}$ & Pass \\
\hline
\end{tabular}

Berdasarkan Tabel 5 dapat dinyatakan bahwa desain memenuhi kriteria stabilitas pada kondisi saat kapal dimuati penuh (20 penumpang).

\section{Perhitungan Trim}

Trim dapat didefinisikan sebagai perbedaan tinggi sarat air pada haluan dan buritan kapal. Berdasarkan NCVS Indonesian Flag Chapter II, Section 37.8.1 [17], nilai trim untuk kapal dengan panjang kurang dari 35 meter tidak boleh lebih dari Lpp/50. Dari hasil analisis yang diperoleh bersama koreksi stabilitas dengan menggunakan bantuan software stabilitas pada semua kondisi pemuatan, koreksi aktual trim kapal memenuhi krtiteria seperti pada Tabel 6 .

Tabel 6.

Nilai trim kapal penumpang pada setiap kondisi pemuatan

\begin{tabular}{llrrl}
\hline \hline Kondisi Muatan & Kriteria & Nilai $(\mathrm{m})$ & Aktual $(\mathrm{m})$ & Status \\
\hline 20 orang penumpang & Lpp/50 & 0.19 & 0.033 & Pass \\
20 orang penumpang & Lpp/50 & 0.19 & 0.016 & Pass \\
menumpuk & Lpp/50 & 0.19 & 0.055 & Pass \\
10 orang penumpang & Lpp/50 & 0.19 & 0.038 & Pass \\
$\begin{array}{l}10 \text { orang penumpang } \\
\text { menumpuk }\end{array}$ & Lpp/50 & 0.19 & 0.083 & Pass \\
Penumpang kosong & & & & \\
\hline \hline
\end{tabular}

\section{Pembuatan Rencana Garis}

Proses pembuatan desain Rencana Garis pengerjaanya dapat dimulai setelah pengerjaan model lambung selesai. Penyempurnaan desain Rencana Garis dapat dilakukan dengan bantuan software CAD (Computer Aided Design). Adapun desain Rencana Garis kapal penumpang bertenaga surya ini dapat dilihat pada Gambar 4.
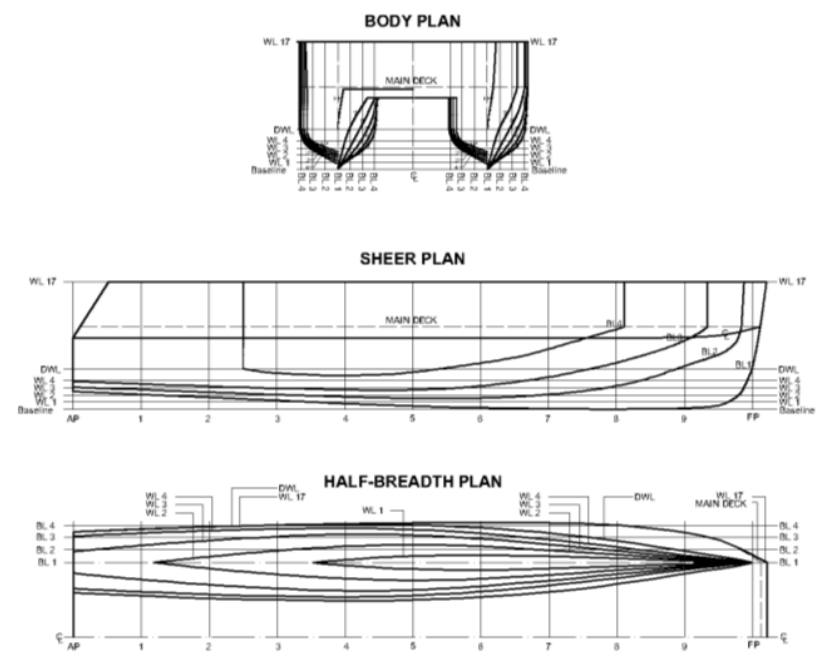

Gambar 4. Desain Rencana Garis lambung kapal penumpang (water bus) dengan tipe katamaran.

\section{N. Pembuatan Rencana Umum}

Dari gambar Rencana Garis yang sudah di buat, maka dapat dibuat pula gambar Rencana Umum. Hal yang perlu di perhatikan dalam membuat Rencana Umum kapal penumpang katamaran adalah penataan ruang dan peralatan 
pada geladak utama [18] agar memberikan ruang yang leluasa dan akses yang cukup untuk penumpang dan crew.

Desain water bus ini juga mempertimbangkan akses menuju baterai untuk maintenence dan sirkulasi udara dari dan menuju baterai. Desain dapat dilihat pada Gambar 5.
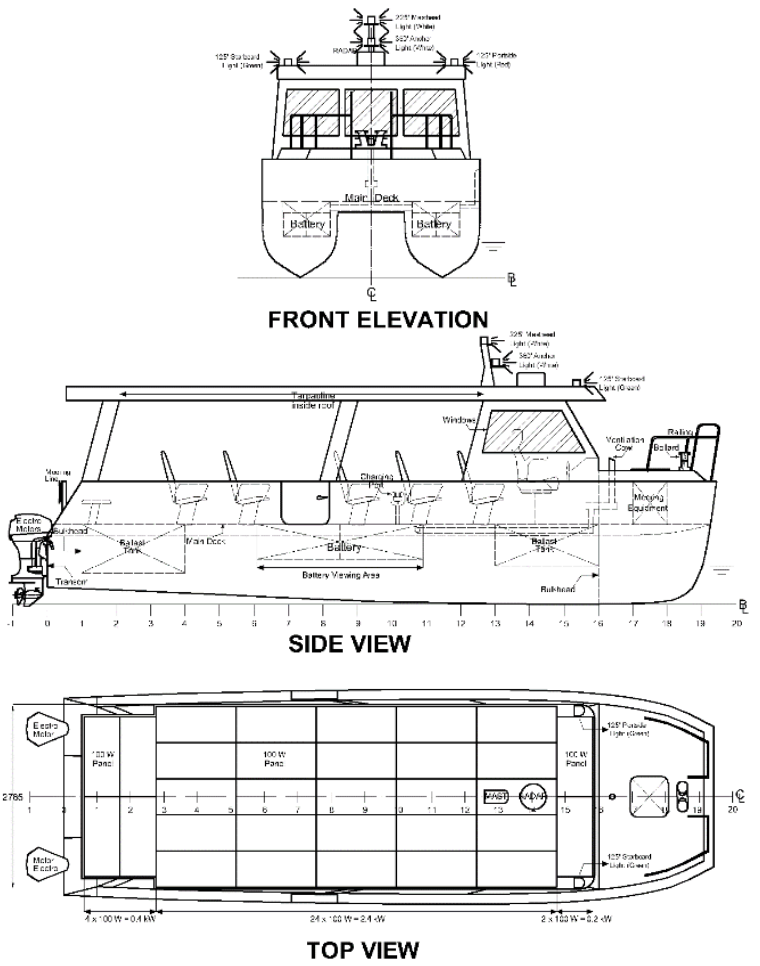

Gambar 5. Desain Rencana Umum kapal penumpang (water bus) yang dilengkapi dengan panel surya sebagai sumber tenaga.

\section{O. Pembuatan Safety Plan}

Safety plan dibuat dengan menggunakan gambar Rencana Umum. Gambar Safety Plan Arrangement didefinisikan sebagai perencanaan keselamatan dengan fungsi dan perlengkapan pada kapal. Perencanaan jumlah dan tata letak peralatan keselamatan di laut diatur dalam Non-Convention Vessel Standard (NCVS) Chapter IV [19] tentang perlengkapan keselamatan.

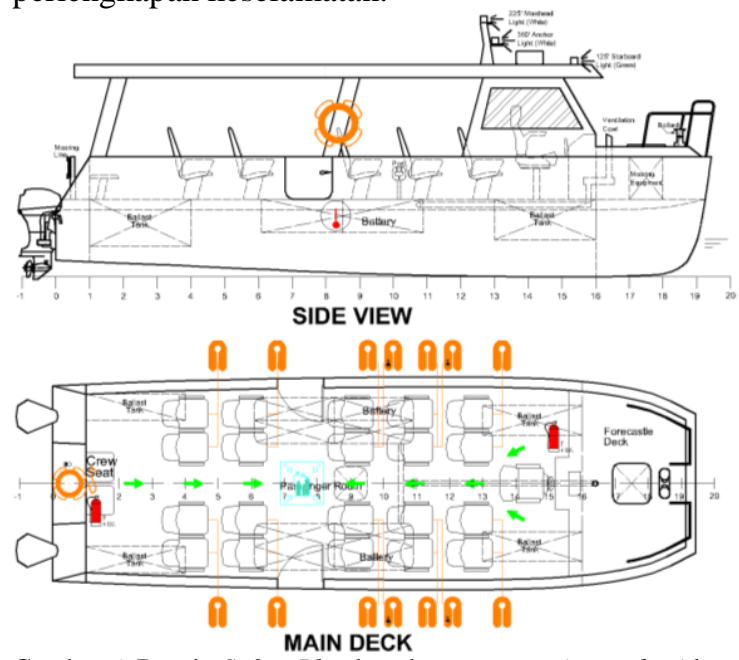

Gambar 6. Desain Safety Plan kapal penumpang (water bus) katamaran.

\section{P. Pembuatan Desain 3 Dimensi}

Desain 3 Dimensi ini dilakukan untuk melihat hasil perancangan kapal dari berbagai sudut pandang. Untuk desain 3 dimensi dapat dilihat pada Gambar 7(a) dan Gambar 7(b).

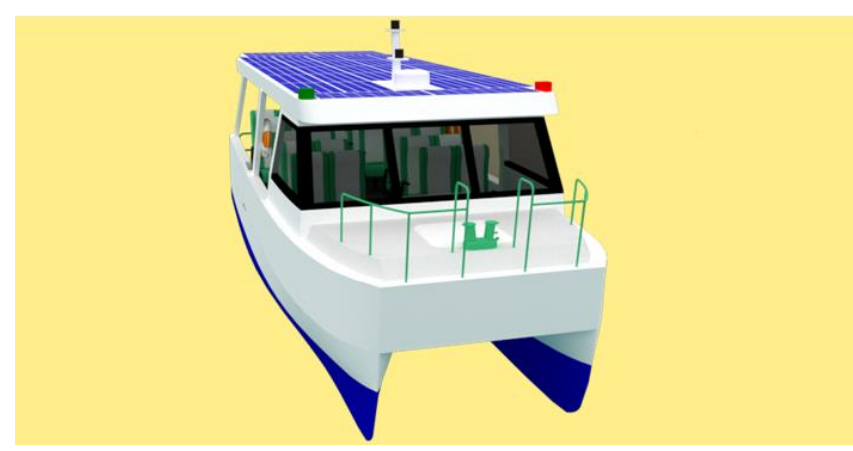

(a)

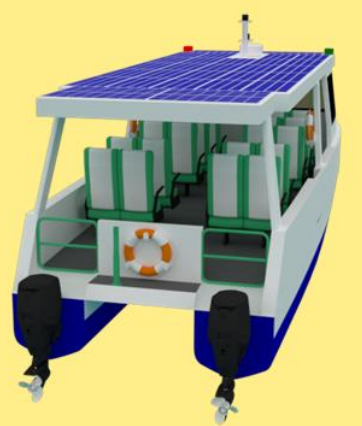

(b)

Gambar 7. (a). Tampak perspektif depan desain 3 Dimensi kapal penumpang (waterbus) katamaran (b). Tampak perspektif belakang desain 3 Dimensi kapal penumpang (waterbus) katamaran.

\section{KESIMPULAN}

Desain water bus dengan payload 20 penumpang untuk rute yang telah ditentukan. Ukuran utama kapal, yaitu :

$$
\begin{aligned}
\text { LOA } & =9.71 \mathrm{~m} \\
\mathrm{Lwl} & =9.52 \mathrm{~m} \\
\mathrm{~B} & =3.15 \mathrm{~m} \\
\mathrm{~T} & =0.56 \mathrm{~m} \\
\mathrm{H} & =1.17 \mathrm{~m} \\
\mathrm{~B} 1 & =1.06 \mathrm{~m} \\
\mathrm{~S} & =2.09 \mathrm{~m} \\
\mathrm{Vs} & =11 \mathrm{knots}=5,66 \mathrm{~m} / \mathrm{s} \\
\Delta & =5.041 \text { ton }
\end{aligned}
$$

Desain Rencana Garis (Linesplan), Rencana Umum (General Arrangement), Desain Safety Plan, Desain 3 Dimensi kapal penumpang bertenaga surya.

Daya panel surya sebesar $=3000 \mathrm{Wp}$ dengan Kapasitas baterai sebesar $=75 \mathrm{Kwh}$

\section{DAFTAR PUSTAKA}

[1] I. Fitriana, A. Sugiyono, and L. Wahid, "Outlook Energi Indonesia 2017," Jakarta, 2016.

[2] Beritajakarta, "Pasokan BBM Telat, KM Kerapu Tak Beroperasi," www.beritajakarta.id, 2016. [Online]. Available: http://www.beritajakarta.id.

[3] F. Yousif, M. Alghoul, A. Ebrahim, N. Asim, and K. Sopian, "Simulation of Hybrid PV-'3 Phase Grid' Electric Vehicle Charging System," in 7th International Conference on Renewable Energy Sources (RES '13), 2013.

[4] Inrix, "Global Traffic Scorecard." [Online]. Available: http://inrix.com/ .

[5] D. Watson, "Practical Ship Design," Elsevier, vol. 1, 1998

[6] A. Jamaluddin, I. K. A. P. Utama, and M. A. Hamdani, "Kajian interferensi koefisien hambatan pada lambung katamaran melalui komputasi 'slender body method'," Kapal J. Ilmu Pengetah. dan Teknol. Kelaut., vol. 7, no. 2, pp. 1-9, 2010.

[7] M. Moustafa and E. E. El-bokl, "Solar Energy For River Nile Cruisers," 2014. [Online]. https://pdfs.semanticscholar.org/. .

[8] A. Nasirudin, R.-M. Chao, and I. K. A. P. Utama, "Solar powered boat design optimization," Procedia Eng., vol. 194, pp. 260-267, Jan. 2017. 
[9] R. Putera, "Desain Kapal Penumpang Di Banjir Kanal Timur Sebagai Moda Transportasi Alternatif Untuk Mengatasi Kemacetan," Surabaya, 2017.

[10] A. F. Insel, M. \& Molland, An Investigation Into The Resistance Components of High Speed Displacement Catamarans. London: RINA, 1992.

[11] Catamaransite, "Catamaran Hull Design Formulas," 2018 [Online]. Available: http://www.catamaransite.com/.

[12] J. D. van Manen and V. Oossanen, P. Resistance. In : Lewis, E.V. (ed.). Principles of Naval Architecture. The Society of Naval Architects and Marine Engineers, 1988.

[13] M. Rumbayan, A. Abudureyimu, and K. Nagasaka, "Mapping of solar energy potential in Indonesia using artificial neural network and geographical information system," Tokyo, 2011.

[14] Biro Klasifikasi Indonesia, "Rules for The Clasification and
Construction Part.3 Special Ships," in Rules for Small Vessel Up to 24 Meters, 2013.

[15] Kementrian Perhubungan, "Non-Convention Vessel Standard Indonesian Flagged Chapter VI," Jakarta, 2009.

[16] 2000 HSC Code, "International Code of Safety for High-Speed Craft," 2008.

[17] Kementrian Perhubungan, "Non-Convention Vessel Standard Indonesian Flagged Chapter II," Jakarta, 2009.

[18] R. Taggart, Ship Design \& Construction. United State of America: The Society of Naval Architects and Marine Engineers, 1980

[19] Kementrian Perhubungan, "Non-Convention Vessel Standard Indonesian Flagged Chapter IV," Jakarta, 2009. 